\title{
PRAIRIE DOGS AND FERRETS
}

At an executive meeting at Davidson on January 16,1965, it was announced that arrangements were being made by the Saskatchewan Department of Natural Resources to turn over the lease of a quarter section of land, with a thriving colony of about 400 prairie dogs, to the Saskatchewan Natural History Society. This quarter section is in the Frenchman River valley east of Val Marie (NE 23-2-13 w3). We owe a debt of gratitude to Mr. E. Purask, who kindly relinquished his lease on the quarter. The land was then transferred from the jurisdiction of the Department of Agriculture to Natural Resources; shortly it will apparently be in our hands. This forward step in the protection of a rare Canadian mammal is the result of efforts by our Society, and we should all feel some pride in this accomplishment. Incidentally, if you have visited the Museum of Natural History in Regina then you have already seen a view of this colony, for the prairie dog exhibit in the museum depicts this area.

In a letter recently published in the colourful magazine Animals (for 3 November, 1964; 5:120), Jennifer Fisher reports a possible observation of the rare Black-footed. Ferret by her parents at Bellevue, Alberta. This is in the foothills of the Rocky Mountains in southern Alberta. We have written to Miss Fisher for further details.

The Black-footed Ferret is a large weasel which is more robust and minklike than our other native weasels. It has pale yellowish upper-parts with a distinctive broad black band across its eyes like a mask. The larger males may be 23 inches in total length, including the black-tipped tail which is about five inches long. Its feet, as the name suggests, are blackish. Our various weasels feed on a variety of animals in accordance with their size. The small Least Weasel feeds mainly on mice, whereas the larger Lcng-tailed Weasel can take rabbits and other equally large prey. The Black-footed Ferret, which is the largest weasel, preys mainly upon prairie dogs. It is a rare and little known mammal which few people have had the privilege of ever seeing. We would be pleased to hear from anyone who may have information about wild ferrets.

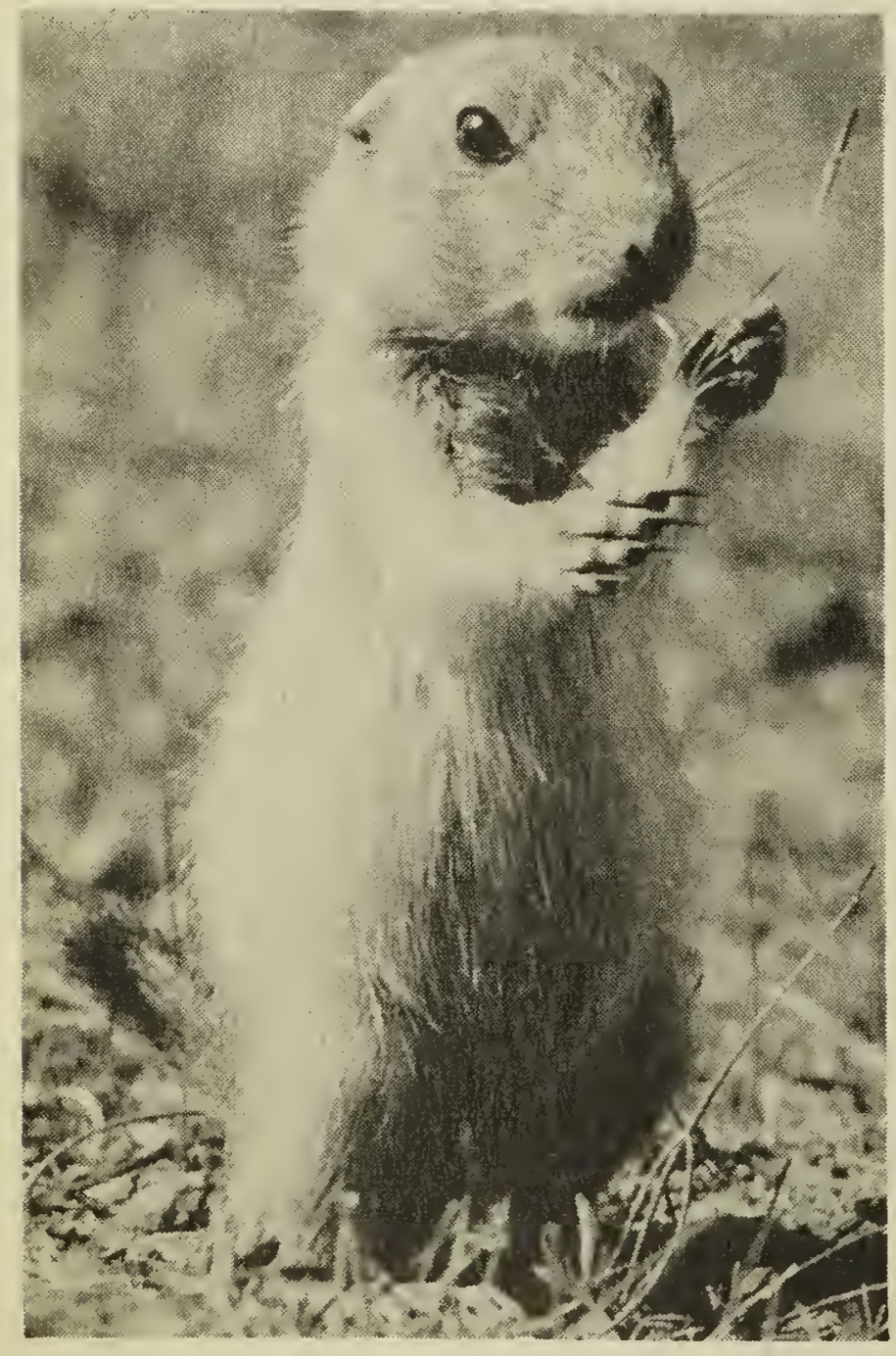

Photo by R. R. Taylor

Black-tailed Prairie Dog

The status of the Black-footed Ferret (Mustela nigripes) has recently been reviewed by Charles L. Homolka in Audubon (July-August, 1964; 66: 244-246). The range of this vanishing species "apparently has coincided with that of the prairie dog on which it preys." Homolka's detailed map of the present range of the ferret does not include Canada, although there are early records for Alberta and, especially, Saskatchewan. In Canada, there are more museum specimens of ferrets than may ever occur here again, but mainly because of the lack of a food source. The continuing widespread poisoning of the prairie dog is doubtless eliminating other associated wildlife species. In our discussions of the need for preservation of the Blacktailed Prairie Dog colonies in this province we have said little about the ferret. It may well be that by protecting as large a number of prairie dogs as possible we may also be extending a lifeline to the ferret. 